\title{
Experimental design for the optimization of coacervative extraction of brilliant green in water samples using anionic surfactant
}

\author{
Seyed Saheb Sadat Hosseini ${ }^{1}$. Somayeh Khezri ${ }^{2} \cdot$ Amir Khosravi $^{2}$
}

Received: 3 March 2017 / Accepted: 17 June 2018 / Published online: 26 June 2018

(c) The Author(s) 2018

\begin{abstract}
A new and simple method for the determination of trace amounts of brilliant green was developed by coacervative extraction and spectrophotometry. The method is based on the extraction of brilliant green with coacervates made up of sodium dodecyl sulfate as an anionic surfactant, in the presence of saturated $\mathrm{NaCl}$ solution. The effect of various experimental parameters such as $\mathrm{pH}$ of solutions, concentration of surfactant and concentration of salt was investigated using central composite design based on response surface methodology. Under the optimum conditions the calibration graph was linear in the range of $0.03-2.2 \mu \mathrm{g} \mathrm{mL} \mathrm{L}^{-1}$ with a detection limit of $0.012 \mu \mathrm{g} \mathrm{mL}{ }^{-1}$. The relative standard deviation for seven replicates of $1.2 \mu \mathrm{g} \mathrm{mL} \mathrm{m}^{-1}$ brilliant green was $1.75 \%$. The proposed method was successfully applied for the determination of brilliant green in different real samples including fish farming water, river water and tap water samples.
\end{abstract}

Keywords Coacervative extraction $\cdot$ Spectrophotometry $\cdot$ Brilliant green $\cdot$ SDS $\cdot$ Experimental design

\section{Introduction}

Brilliant green (BG) is a triphenylmethane dye that has been used as antiseptic and fungicide in fisheries and aquaculture. This dye is effective in the prevention and treatment of certain fish disease (Culp et al. 2006). It has also been used widely in dyeing cotton and paper industry for the production of cover paper (Mall et al. 1996; Srivastava et al. 2005; Mane et al. 2007). However, like two other dyes in the triphenylmethane family (malachite green and crystal violet), BG has generated critical concerns regarding its use in aquaculture, due to its reported toxic effects. It is readily absorbed into fish tissue from water and then causes serious damage to fish internal organs. Also, this dye has mutagenic and carcinogenic effects that affect human health (Dutta 1994; McKay et al. 1985; Krishna and Bhattacharyya 2003). Thus, the use of BG has been banned in many countries including the USA, Canada and the European Union (Plakas et al. 1995).

Somayeh Khezri

s_khezri65@yahoo.com

1 University of Applied Science and Technology, Tehran, Iran

2 Young Researchers and Elites Club, North Tehran Branch, Islamic Azad University, Tehran, Iran
However, this hazardous dye is still being used in many parts of the world due to its low cost, high efficiency and easy accessibility. Therefore, the development of a sensitive and reliable method is essential for the determination of BG in various water samples. Several methods such as adsorption, chemical oxidation, dosimetry and membrane processes have been reported for the determination and removal of this dye (Robinson et al. 2001; Santhy and Selvapathy 2006; Lin and Lin 1993; Georgiou et al. 2003; Sarasa et al. 1998; Allegre et al. 2006; Fersi et al. 2005; Khan et al. 2002). Most of these methods are expensive and require time-consuming and complicated instruments. The use of cloud point extraction (CPE) has gained considerable attention in the last few years, as it has an important potential to concentrate a wide variety of toxic elements while providing good recycling characteristics and high preconcentration yield in water samples. Nonionic surfactants, such as Triton X-100 and Triton X-114, have been widely used as the extracting agents for various compounds (Liu et al. 2007; Niazi et al. 2007). Recently, coacervative extraction method (CAE) has been used for the extraction of various organic compounds and metal ions from environmental and biological liquid samples which is similar to CPE procedure (Yazdi 2011; Ballesteros-Gomez et al. 2010; Rubio and Perez-Bendito 2003; Bahram et al. 2015; Kukusamude et al. 2016; Hagarova et al. 2013; Melnyk et al. 2014, 2015; Zhao et al. 2017; 
Xu et al. 2017), but it should be noted that CPE involves the phase separation of neutrally charged (nonionic or zwitterionic) surfactants induced by the temperature, while CAE involves phase separation of ionic amphiphiles induced by other parameters (e.g., addition of electrolytes, $\mathrm{pH}$ change, addition of organic co-solvents, or simple mixing of oppositely charged amphiphiles) (Yazdi 2011). In CPE methods, high temperatures (sometimes $>70^{\circ} \mathrm{C}$ ) may affect the stability of the compounds of interest, but in the CAE method the clouding phenomenon can occur with anionic surfactants at low temperature and this procedure had no effect on the stability of the compounds (Shemirani et al. 2004; Sicilia et al. 2002). Recently, micelle-mediated extraction using anionic surfactant has been applied for preconcentration and determination of malachite green in water samples, simultaneous determination of $\mathrm{Co}$ (II) and $\mathrm{Ni}$ (II), and spectrophotometric determination of $\mathrm{Pb}$ (II) and $\mathrm{Cu}$ (II) by Bahram et al. (Bahram and Khezri 2012; Bahram et al. 2011; 2013). In fact, all of these procedures are kinds of CAE method that are performed at low temperature and give high recovery and low limit of detection (Shemirani et al. 2004; Sicilia et al. 2002; Bahram and Khezri 2012; Bahram et al. 2011, 2013). To the best of our knowledge, no applications of coacervative extraction method using anionic surfactants for preconcentration and spectrophotometric determination of brilliant green have been previously reported. Several advantages are provided using anionic surfactant for CAE: (a) possibility of performing extractions at low temperatures, (b) the extraction can be carried out in a short time since equilibration time is not required (rapidity) and (c) these surfactants are absorbance-free in the UV-Vis region (Shemirani et al. 2004; Sicilia et al. 2002). Micellar aqueous solution is produced by the addition of surfactant. The concentration at which surfactants begin to form micelle is known as the critical micelle concentration (CMC). The amount of surfactant added must be such to ensure the formation of micelle aggregates in the solution. (The final surfactant concentration must exceed the CMC of that surfactant.) The CMC of a surfactant depends on several factors, such as its molecular structure and experimental conditions such as ionic strength, counterions, temperature. Upon appropriate alteration of the conditions such as temperature or pressure, addition of salt or other additives, the solution becomes turbid due to the diminished solubility of the surfactant in water. Once the surfactant concentration exceeds the CMC and the solution becomes cloudy, the aqueous micellar solution separates into two isotropic phases: a surfactant-rich phase of small volume and a surfactant-poor phase of much higher volume (aqueous). Any component that binds to the micellar aggregate in solution can be extracted from the original solution and therefore be concentrated in the surfactant-rich phase (Depoi et al. 2012; Filik and Cekic 2011). In this work CAE extraction using an anionic surfactant, namely sodium dodecyl sulfate (SDS), was applied to the preconcentration and determination of BG in water samples. The method is based on the extraction of BG with coacervates made up of SDS in the presence of saturated $\mathrm{NaCl}$ solution. For preconcentration purpose, $0.06 \% \mathrm{w} / \mathrm{v}$ aqueous solution of SDS in the micelle form, saturated solution of $\mathrm{NaCl}$ and aqueous sample were mixed and then kept in an ice bath. Thereby, cloud point or turbidity was obtained. The mixture was centrifuged to separate the surfactant-rich phase containing the analyte of interest. The surfactant-rich phase was diluted with a mixture of acetonitrile and water (1: 1) before being detected by spectrophotometric method. In this work the effects of various experimental parameters for preconcentration and determination of BG were investigated. Central composite design (CCD) and response surface methodology (RSM) were used for designing the experiments and optimization purpose.

\section{Experimental}

\section{Apparatus}

A Jasco Model 7850 UV-Visible spectrophotometer with $1-\mathrm{cm}$ quartz cell $(0.5 \mathrm{~mL})$ was used for recording the absorption spectra and absorbance measurements. A centrifuge (4000 rpm, UromAzma Co.) was applied to accelerate the phase separation process. A Metrohm model 632 $\mathrm{pH}$ meter with a combined glass electrode was used for $\mathrm{pH}$ measurements.

\section{Reagents}

All chemicals used in the experiments were of analytical grade and used without further purification. All solutions were prepared with distilled water. All chemicals were purchased from Merck (Darmstadt, Germany). A stock solution of $10^{-3} \mathrm{~mol} \mathrm{~L}^{-1}$ of BG was prepared by dissolving appropriate amount of BG in water. Working solutions were prepared by suitable dilution of the stock solution with distilled water. Aqueous $1 \%(\mathrm{w} / \mathrm{v})$ solution of SDS was prepared by dissolving $1 \mathrm{~g}$ of SDS in $100 \mathrm{~mL}$ of hot distilled water. A phosphate buffer with a $\mathrm{pH}$ value of 4 was prepared by using phosphoric acid and sodium hydroxide at appropriate concentrations. The $\mathrm{pH}$ value was adjusted with a $\mathrm{pH}$ meter. A saturated solution of sodium chloride was prepared by dissolving appropriate amount of $\mathrm{NaCl}$ in water.

\section{Statistical software}

Essential Regression and Experimental Design for chemists and Engineers (EREGRESS), as MS Excel add-in software 
(Stephan et al. 1998-2001; Bulacov et al. 2006), was used to design the experiments and to model and analyze the results.

\section{Central composite design}

CCD was used to optimize the experimental variables. Three independent factors, namely the concentration of SDS $(F 1)$, $\mathrm{pH}(F 2)$ and added volume of saturated $\mathrm{NaCl}(F 3)$, were studied at five levels with four repeats at the central point, using a circumscribed CCD. For each of the three studied variables, high (coded value: +1.428 ) and low (coded value: -1.428 ) set points were selected as shown in Table 1.

Also Table 2 shows the coded and actual values of designed experiments based on CCD methodology obtained using EREGRESS software.

For a special response, polynomial equations and response surface were produced using EREGRESS. For an experimental design with three factors, the model including linear, quadratic and cross-terms can be expressed as Eq. (1).

$$
\begin{aligned}
\text { Response }= & b 0+b 1 \times F 1+b 2 \times F 2+b 3 \times F 3 \\
& +b 4 \times F 1 \times F 1+b 5 \times F 2 \times F 2 \\
& +b 6 \times F 3 \times F 3+b 7 \times F 1 \times F 2 \\
& +b 8 \times F 1 \times F 3+b 9 \times F 2 \times F 3 .
\end{aligned}
$$

Within Eq. (1), $F 1-F 3$ are the variable parameters and $b 0-b 9$ are the coefficient values achieved through multiple linear regression (MLR) using EREGRESS. The response surface graphs were obtained through a statistical process describing the design and the modeled CCD data. Response surface methodologies graphically demonstrate relationships between parameters and responses and are the way to achieve an exact optimum (Stephan et al. 1998-2011; Bulacov et al. 2006; Siouf and Phan-Tan-Luu 2000; Lundstedt et al. 1998; Araujo and Brereton 1996).

The statistical significance of the predicted models was evaluated by the analysis of variance (ANOVA) and least squares techniques. The ANOVA consists in determining which of the factors significantly affect the response variables studied, using a Fisher's statistical test $(F$ test). The importance and the magnitude of the estimated coefficients of each variable and all their possible interactions on the response variables were determined. Such coefficients for each variable represent the improvement in the response,
Table 2 List of experiments in the CCD for model optimization: coded and (actual) values

\begin{tabular}{lllll}
\hline Factor levels & & & & \\
\hline Design points & F1 & F2 & F3 & Response \\
\hline 1 & $0(0.055)$ & $1.428(10)$ & $0(0.55)$ & 0.269 \\
$2^{(\mathrm{cp})}$ & $0(0.055)$ & $0(5.5)$ & $0(0.55)$ & 0.336 \\
3 & $-1(0.028)$ & $1(8.1)$ & $-1(0.28)$ & 0.207 \\
4 & $-1(0.028)$ & $-1(2.8)$ & $1(0.81)$ & 0.32 \\
5 & $1.428(0.1)$ & $0(5.5)$ & $0(0.55)$ & 0.271 \\
6 & $-1(0.028)$ & $-1(2.8)$ & $-1(0.28)$ & 0.206 \\
7 & $-1.428(0.01)$ & $0(5.5)$ & $0(0.55)$ & 0.164 \\
8 & $-1(0.028)$ & $1(8.1)$ & $1(0.81)$ & 0.233 \\
9 & $0(0.055)$ & $-1.428(1)$ & $0(0.55)$ & 0.319 \\
10 & $0(0.055)$ & $0(5.5)$ & $1.428(1)$ & 0.299 \\
$11^{(\mathrm{cp})}$ & $0(0.055)$ & $0(5.5)$ & $0(0.55)$ & 0.336 \\
$12^{(\mathrm{cp})}$ & $0(0.055)$ & $0(5.5)$ & $0(0.55)$ & 0.336 \\
13 & $1(0.081)$ & $1(8.1)$ & $-1(0.28)$ & 0.264 \\
14 & $1(0.081)$ & $-1(2.8)$ & $1(0.81)$ & 0.327 \\
15 & $0(0.055)$ & $0(5.5)$ & $-1.428(0.1)$ & 0.26 \\
16 & $1(0.081)$ & $-1(2.8)$ & $-1(0.28)$ & 0.223 \\
17 & $1(0.081)$ & $1(8.1)$ & $1(0.81)$ & 0.282 \\
$18^{(\mathrm{cp})}$ & $0(0.055)$ & $0(5.5)$ & $0(0.55)$ & 0.334 \\
\hline
\end{tabular}

${ }^{(\mathrm{cp})}$ Indicates four repeats of center points

that is, the variable setting is expected to change from low to high. Effects with less than $95 \%$ of significance (effects with a $p$ value higher than 0.05 ) were discarded and pooled into the error term, and a new analysis of variance was performed for the reduced model. Note that the $p$ value represents a decreasing index of the reliability of a result (Siouf and Phan-Tan-Luu 2000). Replicates $(n=4)$ of the central points were performed to appraise the experimental error.

\section{Extraction procedure}

An aliquot of the BG solution (so that its final concentration would be in the range of $\left.0.03-2.2 \mu \mathrm{g} \mathrm{mL}^{-1}\right), 0.6 \mathrm{~mL}$ SDS $(1 \% \mathrm{w} / \mathrm{v}), 1 \mathrm{~mL}$ of phosphate buffer $(\mathrm{pH} 4)$ and $0.7 \mathrm{~mL}$ of saturated $\mathrm{NaCl}$ were placed in a $15-\mathrm{mL}$ centrifuge tube. The solution was diluted to $10 \mathrm{~mL}$ with distilled water. Afterward, the sample was shaken and let stay in an ice bath for 25 min before centrifugation. A cloudy solution was formed. Separation of two phases was achieved by centrifugation

\begin{tabular}{|c|c|c|c|c|c|}
\hline \multirow[t]{2}{*}{ Variable name } & \multicolumn{5}{|c|}{ Coded factor levels } \\
\hline & -1.428 (low) & -1 & 0 & +1 & +1.428 (high) \\
\hline$F 1 \mathrm{SDS}(\% \mathrm{~W} / \mathrm{V})$ & 0.01 & 0.028 & 0.055 & 0.081 & 0.1 \\
\hline$F 2 \mathrm{pH}$ & 1 & 2.8 & 5.5 & 8.1 & 10 \\
\hline$F 3$ saturated $\mathrm{NaCl}(\mathrm{mL})$ & 0.1 & 0.28 & 0.55 & 0.81 & 1 \\
\hline
\end{tabular}

Table 1 Variables and values used for central composite design 
for $6 \mathrm{~min}$ at $3000 \mathrm{rpm}$. The mixture was cooled in an ice bath in order to increase the viscosity of the surfactant-rich phase, and the aqueous phase was easily decanted by simply inverting the tube. The surfactant-rich phase obtained by this procedure was dissolved and diluted to $0.5 \mathrm{~mL}$ with a mixture of acetonitrile and water (1: 1) and transferred into a $0.5-\mathrm{mL}$ quartz cell to measure the absorbance of the solution at $628 \mathrm{~nm}$ against a reagent blank. The blank solution was prepared in the same manner without BG.

\section{Result and discussion}

\section{Experimental design}

The absorbance of samples in maximum wavelength $(628 \mathrm{~nm})$ was measured in order to optimize three independent factors, namely the concentration of SDS (F1), $\mathrm{pH}(\mathrm{F} 2)$ and $\mathrm{NaCl}(\mathrm{F} 3)$. As mentioned, Tables 1 and 2 represent the levels of coded and actual tested experimental variables. The aims of this CCD strategy were (1) to study the effect of $\mathrm{pH}$, saturated $\mathrm{NaCl}$ and concentration of SDS on the CAE determination of BG; (2) to identify the variables that have a higher impact on the extraction method; (3) to give an insight into the robustness of the procedure close to the optimum conditions; and (4) to eventually show the interactions between the variables. In order to find the important factors and build a model to optimize the procedure, we started with a full quadratic model including all terms of Eq. (1). To obtain a simple and yet realistic model, the unimportant terms $(p>0.05)$ were eliminated from the model through a 'backward elimination' process. The constructed model using all 10 terms of Eq. (1) showed a relatively good fit. For this model, a regression coefficient $\left(R^{2}\right)$ for calibration close to 1 was achieved. Some of these 10 regression variables are insignificant or at least have low significance and should be eliminated from the model. Since $\left(R^{2}\right)$ always decreases when a regression variable is eliminated from a regression model, in statistical modeling the adjusted regression coefficient ( $\left.R^{2} \mathrm{adj}\right)$, which takes the number of regression variables into account, is usually selected (Bulacov et al. 2006; Siouf and Phan-Tan-Luu 2000; Lundstedt et al. 1998; Araujo and Brereton 1996). Also the prediction coefficient $\left(R^{2}\right.$ pred), which shows the predictive power of the model, is chosen for the same reason. This parameter was approximated using the prediction error sum of squares or PRESS that was calculated from residuals, which are based on a regression model with one data point removed. So, $R^{2}$, adjusted $R^{2}\left(R^{2}\right.$ adj) and $R^{2}$ for prediction $\left(R^{2}\right.$ pred $)$ together are very convenient to get a quick impression of the overall fit of the model and the predictive power based on one data point removed. In a good model, these parameters should not be too different from each other. However, for small data sets, it is very likely that every data point is influential. In these cases, a high value for $R^{2}$ for prediction ( $R^{2}$ pred) cannot be expected (Bulacov et al. 2006). By the elimination of insignificant parameters from Eq. (1), calibration $R^{2}$ decreased finally to 0.933 , but adjusted $R^{2}$ $\left(R^{2} \mathrm{adj}\right)$ and $R^{2}$ for prediction $\left(R^{2}\right.$ pred) increased nearly to 0.887 and 0.703 , respectively. The obtained reduced models using significant linear, quadratic and interaction parameters are shown in Table 3. (It should be mentioned that the regression equation was obtained using un-coded values of parameters.) For this case, the adjusted $R^{2}$ was well within the acceptable limits and there were no large
Table 3 Some characteristics of the constructed models

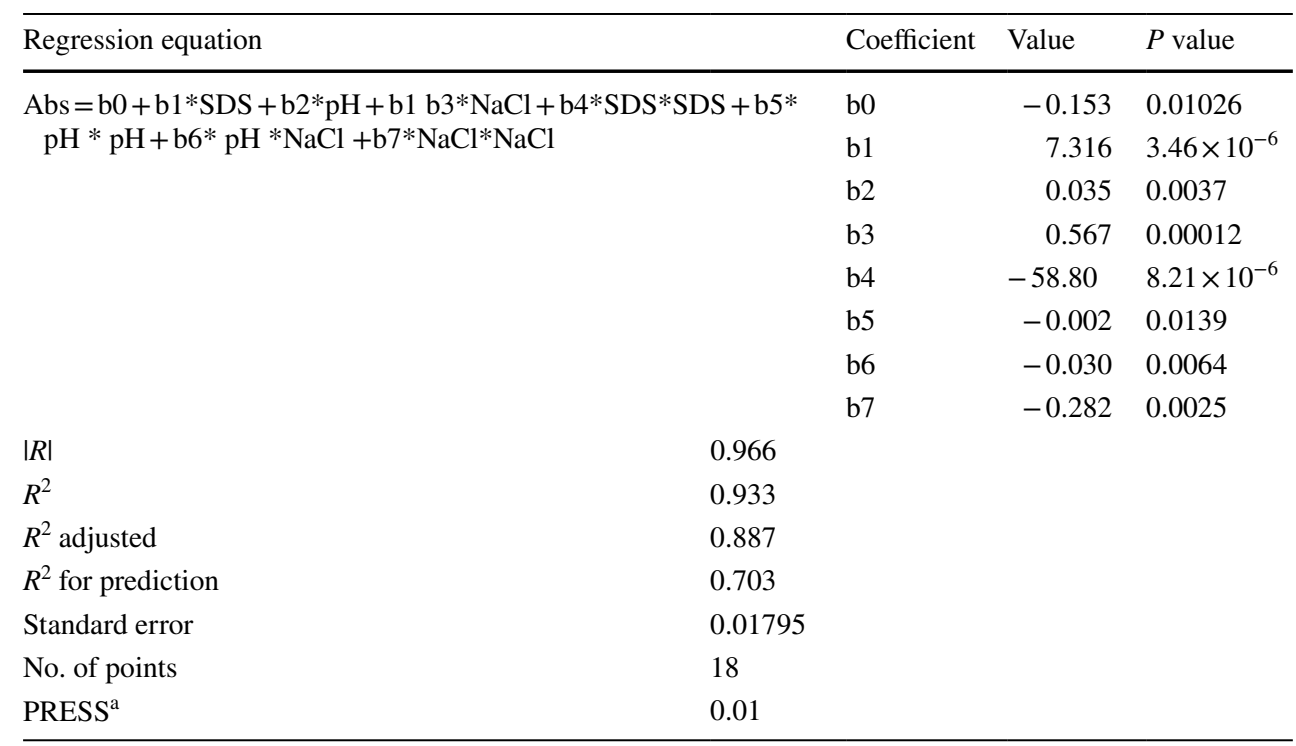

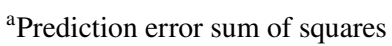


Fig. 1 Response surface of full quadratic model between absorbance and the three variables: concentration of SDS amount (F1), pH (F2) and added volume of saturated solution of $\mathrm{NaCl}$ (F3): a response surface plot for the effect of concentration of SDS amount and added volume of saturated solution of $\mathrm{NaCl}$ on the absorbance, when $\mathrm{pH}$ was fixed at 5.5, b response surface plot for the effect of $\mathrm{pH}$ and concentration of SDS amount, when saturated $\mathrm{NaCl}$ was fixed at $0.55 \mathrm{ml}, \mathbf{c}$ response surface plot for the effect of added volume of saturated solution of $\mathrm{NaCl}$ and concentration of SDS amount, when $\mathrm{pH}$ was fixed at 5.5
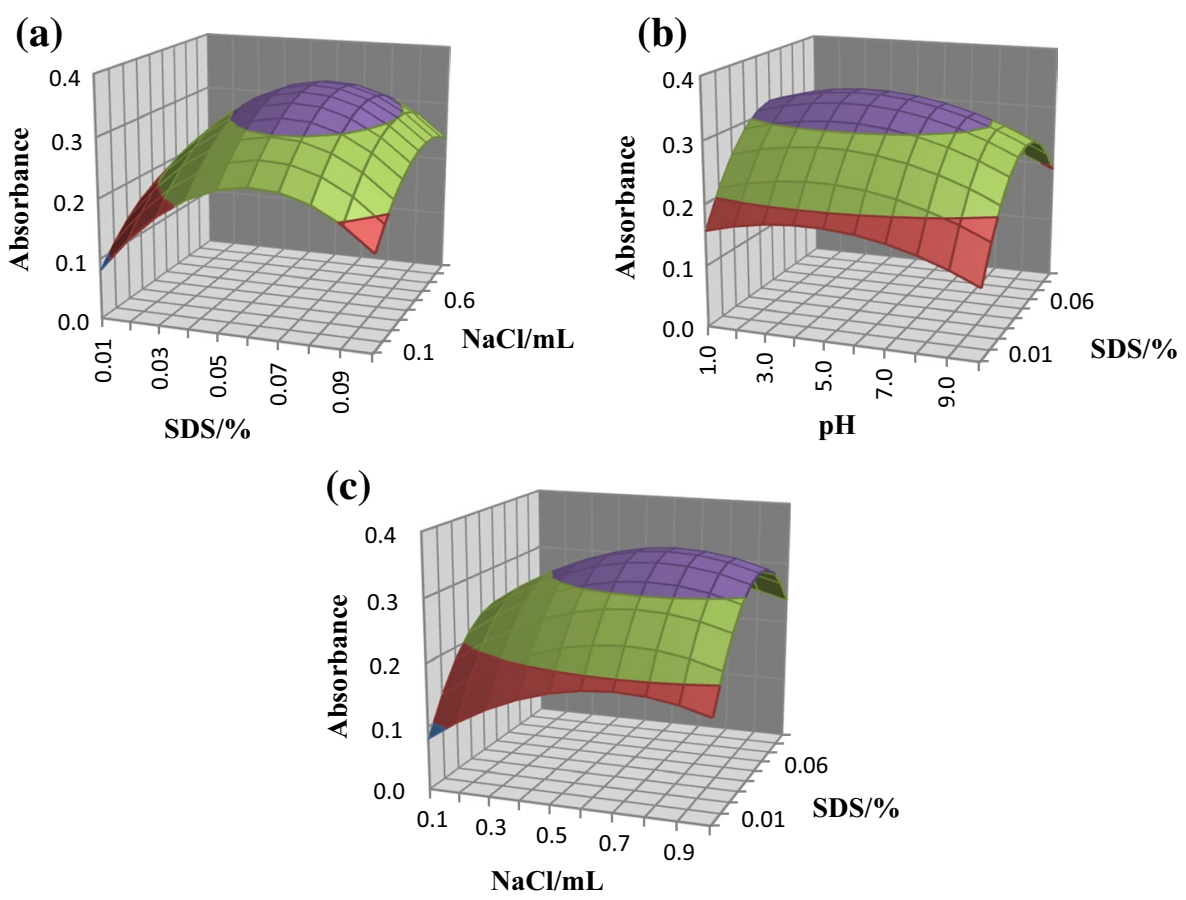

differences between $R^{2}$ values which revealed that the experimental data show a good fit with the third-order polynomial equations.

\section{Response surface and selection of optimum conditions}

In order to gain insight into the effect of each variable, the three-dimensional (3D) plots for the predicted responses were also prepared, based on the model function to analyze the change of response surface. For example, Fig. 1 shows some of the response surface plots that show the relationship between two variables and absorbance of samples, while third variable was kept at a center level.

As shown in Fig. 1 there was a nonlinear relation between the response and variables, because the surface plots of the response showed curves. In Table 3 several linear, squared and interaction parameters are shown which are statistically significant. The selection of optimum conditions for the method is possible from the response surface plots (Fig. 1). These results demonstrate that the response surfaces have a flat optimum. The plots show the interaction between the mentioned factors when the third factor has been fixed at a central point. The results (Fig. 1) show a pronounced dependency of absorbance to all of the investigated experimental variables. Also these plots show that there are interactions between the variables (see Table 3). Finally, optimum conditions were selected from the obtained model for further examination (Table 4).
Table 4 Optimum conditions obtained by response surface methodology

\begin{tabular}{lcl}
\hline Variable name & Optimum values & Selected values \\
\hline$F 1 \mathrm{SDS}(\% \mathrm{w} / \mathrm{v})$ & $0.055-0.065$ & 0.06 \\
$F 2 \mathrm{pH}$ & $4-5$ & 4 \\
$F 3$ saturated $\mathrm{NaCl}(\mathrm{mL})$ & $0.65-0.75$ & 0.7 \\
\hline
\end{tabular}

Table 5 Analytical characteristics of the proposed method

\begin{tabular}{ll}
\hline Linear range $\left(\mu \mathrm{g} \mathrm{mL}^{-1}\right)$ & $0.03-2.2 \mu \mathrm{g} \mathrm{mL}^{-1}$ \\
\hline$R^{2(\mathrm{a})}$ & 0.999 \\
$\mathrm{LOD}\left(\mu \mathrm{g} \mathrm{mL}^{-1}\right)^{(\mathrm{b})}$ & 0.012 \\
Repeatability (RSD) & $(\mathrm{c})$ \\
\hline
\end{tabular}

\footnotetext{
${ }^{\text {(a) }}$ Squared regression coefficient

(b) Limit of detection for $S / N=3$

${ }^{(c)}$ Relative standard deviation for 7 replicate determinations of $1.2 \mu \mathrm{g} \mathrm{mL}^{-1} \mathrm{BG}$
}

\section{Analytical characteristics of the proposed method}

Table 5 summarizes the analytical characteristics of the optimized method, including the regression coefficient, the linear range, the limit of detection and the reproducibility. The limit of detection, defined as $C_{\mathrm{L}}=3 S_{\mathrm{B}} / m$ (where $C_{\mathrm{L}}, S_{\mathrm{B}}$ and $m$ are the limit of detection, standard deviation of the blank and the slope of the calibration graph, 
Table 6 Tolerance limit of foreign ions on the determination of $0.15 \mu \mathrm{g} \mathrm{mL}^{-1}$ of BG

\begin{tabular}{ll}
\hline Foreign ions & Tolerance ratio \\
\hline $\mathrm{Co}^{2+}, \mathrm{Pb}^{2+}, \mathrm{Li}^{+}, \mathrm{Cd}^{2+}, \mathrm{Al}^{3+}, \mathrm{K}^{+}, \mathrm{Na}^{+}, \mathrm{Li}^{+}, \mathrm{NO}_{3}^{-}$, & 1000 \\
$\mathrm{SO}_{4}{ }^{2-}$ & \\
$\mathrm{Mg}^{2+}, \mathrm{Zn}^{2+}, \mathrm{Cu}^{2+}$ & 800 \\
$\mathrm{Cl}^{-}, \mathrm{Br}^{-}, \mathrm{I}^{-}, \mathrm{Ni}^{2+}, \mathrm{CH}_{3} \mathrm{COO}^{-}$ & 600 \\
\hline
\end{tabular}

Table 7 Preconcentration and spectrophotometric determination of BG in the spiked water samples by the proposed method

\begin{tabular}{llll}
\hline Sample & $\begin{array}{l}\text { Added } \\
\left(\mu \mathrm{gL}^{-1}\right)\end{array}$ & Found $\left(\mu \mathrm{g} \mathrm{mL}^{-1}\right)$ & Recovery $(\%)$ \\
\hline Tap water & - & $<$ LOD & - \\
& 0.3 & 0.31 & 103.3 \\
& 1.2 & 1.25 & 104.2 \\
Fish farming water & - & $<\mathrm{LOD}$ & - \\
& 0.3 & 0.325 & 108.3 \\
& 1.2 & 1.28 & 106.7 \\
River water & - & $<\mathrm{LOD}$ & - \\
& 0.3 & 0.29 & 96.66 \\
& 1.2 & 1.23 & 102.5 \\
\hline
\end{tabular}

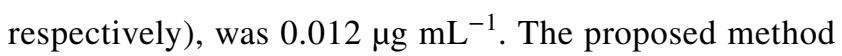
showed an excellent repeatability (RSD $<5 \%$ for 7 replicate determinations of $1.2 \mu \mathrm{g} \mathrm{mL}^{-1} \mathrm{BG}$ ) using the optimum values obtained through CCD.

\section{Interferences}

In order to study the selectivity of the proposed method, the effect of various cations and anions on the preconcentration and determination of $0.15 \mu \mathrm{g} \mathrm{mL}{ }^{-1}$ BG was tested under the optimum conditions. An ion was considered as interferent when it caused a variation in the absorbance of the sample greater than $\pm 5 \%$. As the results show in Table 6 , large excess amounts of common cations and anions do not interfere with the determination of BG. Thus, a very good selectivity is achieved. Also the interferences of two anionic dyes, namely methyl orange and Eriochrome Black T, were investigated under the optimum conditions. There was no response for $100 \mu \mathrm{g} \mathrm{mL}^{-1}$ of methyl orange and Eriochrome Black $\mathrm{T}$ using this procedure. These results were probably due to the intermolecular electrostatic repulsion between SDS and these anionic dyes.

\section{Application of the proposed method}

In order to evaluate the analytical applicability of the proposed method it was applied to the determination of trace amount of BG in tap water, fish farming water and river water samples. The water samples were analyzed after filtering through Whatman filter paper. Spiking BG to the water samples performed the validity of the procedure. The results are shown in Table 7 . The good agreement between the results and known values indicated the successful applicability of the proposed method for the determination of BG in real samples.

\section{Conclusion}

The determination of BG in water samples was successfully performed using coacervative extraction and spectrophotometric method. The proposed method is rapid, simple, safe, easy to use and inexpensive. The use of anionic surfactant for the CAE method offers some significant advantages compared with nonionic surfactant micelle-mediated extraction. The method can be performed at low temperature and has no effect on the stability of the compounds of interest. The stability of most chemicals decrease at higher temperatures, and therefore these components cannot be extracted by traditional CPE methods which need the temperature to be increased. The proposed method provides high recovery, low detection limit and uses of salt and avoids using large amount of concentrated acid for extraction. This paper shows that the use of experimental design enabled a subsequent advantage in terms of labor time and number of experiences to optimize the conditions of experiments for CAE and determination of BG. By using central composite design and subsequently response surface methodology the effect of independent variables such as $\mathrm{pH}, \mathrm{NaCl}$ and SDS concentration on the determination of BG were studied and the optimum conditions were obtained; also, the possible interactions between variables were shown. The analysis of spiked samples with good results indicates that this method is suitable for the determination of BG in the real samples.

Open Access This article is distributed under the terms of the Creative Commons Attribution 4.0 International License (http://creativeco mmons.org/licenses/by/4.0/), which permits unrestricted use, distribution, and reproduction in any medium, provided you give appropriate credit to the original author(s) and the source, provide a link to the Creative Commons license, and indicate if changes were made.

\section{References}

Allegre C, Moulin P, Maisseu M, Charbit F (2006) Treatment and reuse of reactive dyeing effluents. J Membr Sci 269:15-34

Araujo PW, Brereton RG (1996) Experimental design II. Optimization. Trends Anal Chem 15:63-70 
Bahram M, Khezri S (2012) Multivariate optimization of cloud point extraction for the simultaneous spectrophotometric determination of cobalt and nickel in water samples. Anal Methods 4:384-393

Bahram M, Khezri S, Esmhosseini M (2011) Experimental design for the optimization of micelle mediated extraction of malachite green using anionic surfactant, sodium dodecyl sulfate. Anal Methods 3:1096-1100

Bahram M, Shahmoradi S, Mozaffari Sh, Niko A, Akbari Dilmaghani K (2013) Cloud-point extraction and selective spectrophotometric determination of $\mathrm{Pb}(\mathrm{II})$ and $\mathrm{Cu}(\mathrm{II})$ using synthesized $\mathrm{N} 1$, N2-diphenylhydrazine-1,2 dicarbothioamide and an anionic surfactant. Jordan J Chem 8:45-55

Bahram M, Nurallahzadeh N, Mohseni N (2015) pH-sensitive hydrogel for coacervative cloud point extraction and spectrophotometric determination of $\mathrm{Cu}$ (II): optimization by central composite design. J Iran Chem Soc 12:1781-1787

Ballesteros-Gomez A, Sicilia MD, Rubio S (2010) Supramolecular solvents in the extraction of organic compounds. A review. Anal Chim Acta 677:108-130

Bulacov I, Jirkovsky J, Muller M, Heimann RB (2006) Induction plasma-sprayed photocatalytically active titania coatings and their characterisation by micro-Raman spectroscopy. Surf Coat Technol 201:255-264

Culp SJ, Mellick PW, Trotter RW, Greenlees KJ, Kodell RL, Beland FA (2006) Carcinogenicity of malachite green chloride and leucomalachite green in B6C3F1 mice and F344 rats. Food Chem Toxicol 44:1204-1212

Depoi FS, Oliveira TCh, Moraes DP, Pozebon D (2012) Preconcentration and determination of $\mathrm{As}, \mathrm{Cd}, \mathrm{Pb}$ and $\mathrm{Bi}$ using different sample introduction systems, cloud point extraction and inductively coupled plasma optical emission spectrometry Anal. Methods 4:89-95

Dutta PK (1994) an overview of textile pollution and its remedy. Indian J Environ Prot 14:443-446

Fersi C, Gzara L, Dhahbi M (2005) Treatment of textile effluents by membrane technologies. Desalination 185:399-409

Filik H, Cekic SD (2011) Pesticides in the modern world-trends in pesticides analysis. Rijeka, In Tech, pp 247-280

Georgiou D, Aivazidis A, Hatiras J, Gimouhopoulos K (2003) Treatment of cotton textile wastewater using lime and ferrous sulfate. Water Res 37:2248-2250

Hagarova I, Bujdos M, Matus P, Kubova J (2013) Coacervative extraction of trace lead from natural waters prior to its determination by electrothermal atomic absorption spectrometry Spectrochim. Acta Part B 88:75-79

Khan M, Chaudhry ZS, Anwer M (2002) Dosimetric characterisation of aqueous solution of brilliant green for low-dose food irradiation dosimetry. Radiat Phys Chem 63:713-717

Krishna G, Bhattacharyya Sarma A (2003) Adsorption characteristics of the dye, brilliant green, on neem leaf powder. Dyes Pigm 57:211-222

Kukusamude Ch, Quirino JP, Srijaranai S (2016) A coacervative extraction based on single-chain and double-chain cationic surfactants. J Chromatogr A 1472:10-15

Lin SH, Lin CM (1993) Treatment of textile waste effluents by ozonation and chemical coagulation. Water Res 27:1743-1748

Liu W, Zhao WJ, Chen JB, Yang MM (2007) A cloud point extraction approach using Triton X-100 for the separation and preconcentration of Sudan dyes in chilli powder. Anal Chim Acta 605:41-45

Lundstedt T, Seifert E, Abramo L, Thelin B, Nyström A, Pettersen J, Bergman R (1998) Experimental design and optimization. Chemom Intell Lab Syst 42:3-40
Mall ID, Upadhyay SN, Sharma YC (1996) A review on economical treatment of wastewaters and effluents by adsorption. Int J Environ Stud 51:77-124

Mane VS, Mall ID, Srivastava VC (2007) Use of bagasse fly ash as an adsorbent for the removal of brilliant green dye from aqueous solution. Dyes Pigm 73:269-278

McKay G, Otterburn MS, Aja JA (1985) Fuller's earth and fired clay as adsorbents for dyestuffs. Water Air Soil Pollut 24:307-322

Melnyk A, Wolska L, Namiesnik J (2014) Coacervative extraction as a green technique for sample preparation for the analysis of organic compounds. J Chromatogr A 1339:1-12

Melnyk A, Namiesnik J, Wolska L (2015) Theory and recent applications of coacervate-based extraction techniques. Trends Anal Chem 71:282-292

Niazi A, Ghasemi J, Yazdanipour A (2007) Simultaneous spectrophotometric determination of nitroaniline isomers after cloud point extraction by using least-squares support vector machines. Spectrochim Acta A 68:523-530

Plakas SM, El Said KR, Stehly GR, Roybal JE (1995) Optimization of a liquid chromatographic method for determination of malachite green and its metabolites in fish tissues. J AOAC Int 78:1388-1394

Robinson T, Muc-Mullan G, Marchant R, Nigam P (2001) Remediation of dyes in textile effluent: a critical review on current treatment technologies with a proposed alternative. Bioresour Technol 77:247-255

Rubio S, Perez-Bendito D (2003) Supramolecular assemblies for extracting organic compounds. Trends Anal Chem 22:470-485

Santhy K, Selvapathy P (2006) Removal of reactive dyes from wastewater by adsorption on coir pith activated carbon. Bioresour Technol 97:1329-1336

Sarasa J, Roche MP, Ormad MP, Gimeno E, Puig A, Ovelleiro JL (1998) Treatment of a wastewater resulting from dyes manufacturing with ozone and chemical coagulation. Water Res 32:2721-2727

Shemirani F, Abkenar SD, Khatouni A (2004) Determination of trace amounts of lead and copper in water samples by flame atomic absorption spectrometry after cloud point extraction. Bull Korean Chem Soc 25:1133-1136

Sicilia D, Rubio S, Bendit DP (2002) Evaluation of the factors affecting extraction of organic compounds based on the acid-induced phase cloud point approach. Anal Chim Acta 460:13-22

Siouf AM, Phan-Tan-Luu R (2000) Optimization methods in chromatography and capillary electrophoresis. J Chromatogr A 892:75-106

Srivastava VC, Mall ID, Mishra IM (2005) Treatment of pulp and paper mill wastewaters with poly aluminium chloride and bagasse fly ash. Physicochem Eng Aspects 260:17-28

Stephan DD, Werner J, Yeater RP (1998-2001) Essential regression and experimental design for chemists and engineers, MS excel add in software package

Xu J, Niu M, Xiao Y (2017) Hexafluoroisopropanol-induced catanionic-surfactants-based coacervate extraction for analysis of lysozyme Anal. Bioanal Chem 409:1281-1289

Yazdi AS (2011) Surfactant-based extraction methods. Trends Anal Chem 30:918-929

Zhao W, Fan Y, Wang H, Wang Y (2017) Coacervate of polyacrylamide and cationic gemini surfactant for the extraction of methyl orange from aqueous solution. Langmuir 33:6846-6856

Publisher's Note Springer Nature remains neutral with regard to jurisdictional claims in published maps and institutional affiliations. 